\title{
Endoscopic ultrasound-guided drainage of the biliary tree in malignant obstruction
}

\author{
Elia Armellini, Fabrizio Mazza, Marco Ballarè, Giulio Donato, Marco Orsello, Pietro Occhipinti \\ Gastroenterology Department, “Maggiore della Carità" Hospital, Novara 28100, Italy.
}

Correspondence to: Dr. Elia Armellini, Gastroenterology Department, "Maggiore della Carità" Hospital, largo Mazzini 18, Novara 28100, Italy. E-mail: elia.armellini@maggioreosp.novara.it

\begin{abstract}
How to cite this article: Armellini E, Mazza F, Ballarè M, Donato G, Orsello M, Occhipinti P. Endoscopic ultrasound-guided drainage of the biliary tree in malignant obstruction. Mini-invasive Surg 2018;2:23.
\end{abstract}

http://dx.doi.org/10.20517/2574-1225.2018.07

Received: 30 Jan 2018 First Decision: 4 Jun 2018 Revised: 22 Jun 2018 Accepted: 25 Jul 2018 Published: 10 Aug 2018

Science Editor: Fernando A. Alvarez Copy Editor: Jun-Yao Li Production Editor: Huan-Liang Wu

\begin{abstract}
Endoscopic retrograde cholangiopancreatography (ERCP) with stenosis stenting is the procedure of choice for treatment of malignant biliary obstruction. It has a low failure rate $(<5 \%-10 \%$ in cases of normal anatomy). The traditional alternative is radiological percutaneous drainage with a variable and non-negligible burden of adverse events. Interventional endoscopic ultrasound offers real-time imaging of the bilio-pancreatic district with the possibility of accessing the main biliary duct and the left hepatic duct from the duodenum or stomach. Consequently, endoscopic ultrasound-guided biliary drainage, including the rendezvous technique, choledochoduodenostomy, and/or hepaticogastro or antegrade stenting, has become a realistic option that offers advantages of a faster and cost-saving procedure since it can be performed immediately after ERCP, thus avoiding repeated sessions and prolonged hospital stays. We describe a case of malignant obstruction of the common bile duct that was drained by creation of choledocho-duodenal anastomosis under ultrasound-guided endoscopy.
\end{abstract}

Keywords: Endoscopic ultrasound, biliary drainage, pancreatic cancer, ultrasound-guided biliary drainagex

\section{INTRODUCTION}

Endoscopic retrograde cholangiopancreatography (ERCP) with stenosis stenting is the procedure of choice for treatment of malignant biliary obstruction. Even though it has a low failure rate, $<5 \%-10 \%$ in cases of normal anatomy. ERCP can be unsuccessful in cases of gastric outlet obstruction or unidentifiable papilla such as duodenal stenosis, post-surgical anatomy, duodenal diverticula, and/or tumor infiltration of the papilla. When ERCP fails, the traditional alternative is percutaneous biliary drainage (PTBD), which has

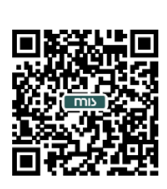


significant morbidity and mortality rates compared with ERCP. Major complication rates after PTBD vary between $0.5 \%$ and $2.5 \%$. Major complications include bleeding, surgical site infections, cholangitis, bile leaks, pneumothorax, and catheter dislodgement. Procedure-related mortality is $<2 \%$ in most series ${ }^{[1]}$.

Endoscopic ultrasound offers real-time imaging of the bilio-pancreatic district with the possibility of guiding complex procedures, including direct access to the main biliary duct and the left hepatic duct from the stomach or duodenum. For these reasons, endoscopic ultrasound-guided biliary drainage (EUS-BD) has been increasingly investigated, and it has been proposed as an alternative to PTBD if ERCP fails. Since Wiersema et al ${ }^{[2]}$ reported the first experience of endosonography-guided cholangiopancreatography, and Giovannini et al. ${ }^{[3]}$ described the creation of a choledochoduodenal anastomosis, various EUS-guided procedures for accessing the biliary tree from the duodenum or stomach have been described. Once a biliary duct has been punctured, either the left intrahepatic ducts from the proximal stomach or the main duct from the duodenal bulb, a tract between the biliary tree and visceral lumen is created by a cystotome and a stent is inserted to allow the creation of an anastomosis. Either plastic or, preferably, self-expandable metal stents can be used, the last being fully or partially covered to minimize the risk of bile leakage. More recently, a novel electro-cautery lumen-opposing self-expanding metal stent (Hot AXIOS ${ }^{\text {mo }}$ stent and delivery system) that is used to perform EUS-BD (choledocho-duodenal anastomosis) has been developed with the promise to allow faster and safer procedures ${ }^{[4]}$.

EUS-BD appears to be an effective technique for the treatment of biliary obstruction after unsuccessful ERCP. However, it is a complex procedure, requiring endoscopic and ultrasonographic skills in addition to an interventional radiology and surgical support in order to ensure a safe procedure in case of adverse events. We herein report a case of successful EUS-DB in a patient with malignant obstruction of the common bile duct, with special emphasis on the technical aspects of this approach including a video of the procedure.

\section{CASE REPORT}

A 71-year-old male patient with biliary obstruction was referred to our department for tissue sampling and endoscopic biliary stenting with the view of further oncological therapy. An abdominal computed tomography $(\mathrm{CT})$ scan showed multiple abdominal adenopathies and pathological tissue involving the hepatic hilum and the pancreatic head with dilation of the main biliary tract and minimal dilation of the intrahepatic biliary tree. After multidisciplinary tumor board evaluation and discussion of the therapeutic options with the patient including the informed consent, he was scheduled for endoscopic drainage. Endoscopy was carried out under deep sedation with midazolam and propofol. During endoscopic exploration, malignant infiltration of the second portion of the duodenum was evidenced, which hindered the procedure after a few ERCP attempts (TJF-240; Olympus Medical Systems, Tokyo, Japan). A stepwise approach was planned during the same endoscopic session. After prophylactic antibiotic therapy was administered (ceftriaxone $2 \mathrm{~g}$ ), a EUS-guided rendezvous was performed with access from the duodenal bulb to the main biliary tract. A 0.025-inch guidewire (VisiGlide II; Olympus Medical Systems, Tokyo, Japan) was passed across the papilla through a $19 \mathrm{G}$ needle (EchoTip Ultra HD Ultrasound Access Needle, Cook Medical, Limerick, Ireland), up to the duodenum. Wire capture via a snare passed through the duodenoscope was unsuccessful due to the difficult duodenal access, and after a few attempts the guidewire had to be retrieved [Figure $1 \mathrm{~A}$ and $\mathrm{B}]$. As a second option, EUS-BD from the duodenal bulb was chosen. A linear echoendoscope with a 3.7-mm working channel (GF-UCT180 Linear Ultrasound Endoscope, Olympus Medical Systems, Tokyo, Japan), connected to an ultrasonographic processor (EU ME2, Olympus Medical Systems, Tokyo, Japan) was used to visualize the main biliary tract from the duodenal bulb. Color Doppler ultrasound was used to assess the local vascularization. The common bile duct was punctured with a 19-gauge needle (EchoTip ${ }^{\circ}$ Ultra HD Ultrasound Access Needle, Cook Medical, Limerick, Ireland). Under fluoroscopic guidance, the bile was aspirated and iodine contrast medium was injected in order to delineate the bili- 

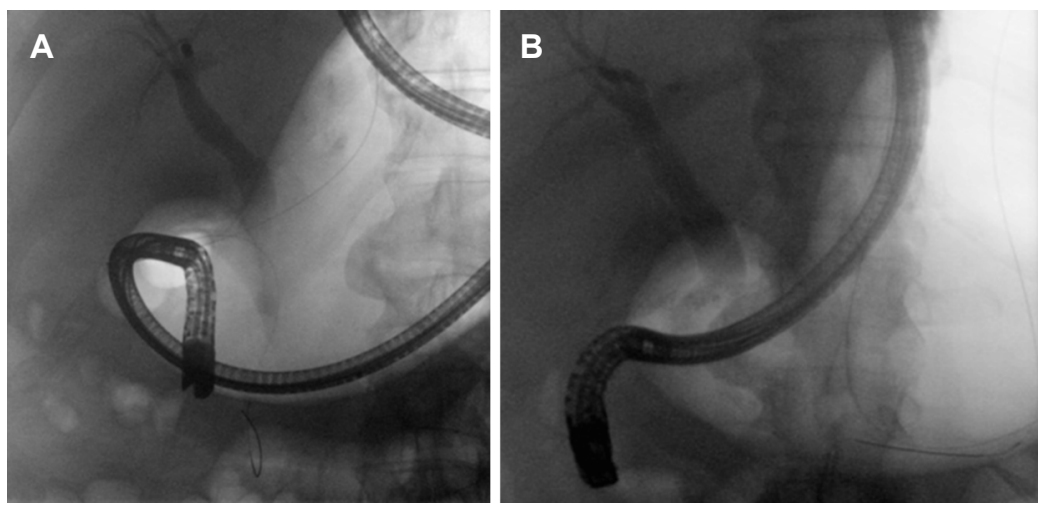

Figure 1. (A) Rendez-vous attempt from the duodenal bulb. The wire was positioned through the papilla, but it could not be retrieved because of the duodenal stenosis. After a few attempts the wire had to be retracted as it can be seen in the stomach (B)

ary tree. A 0.025 -inch guidewire was passed through the $19 \mathrm{G}$ needle that was positioned in the common bile duct, and the 19-gauge needle was then exchanged with a $6 \mathrm{Fr}$ cystotome (Endoflex, Voerde, Germany), which was activated to create a communication between both visceral lumens. A 4-mm biliary dilation balloon (MaxForce ${ }^{\text {Tx }}$ Biliary Balloon Dilatation Catheter, Boston Scientific, Marlborough, USA) was used to dilate the tract and subsequently a preloaded (delivery catheter: $8.5 \mathrm{Fr} / 2.83 \mathrm{~mm}$ ) fully covered $60 \mathrm{~mm} \times 10 \mathrm{~mm}$ self-expandable metal stent (Biliary RX Fully Covered Stent System RMV, Boston Scientific, Marlborough, USA) was easily inserted leading to satisfactory drainage. As a further measure to avoid bile leakage and set the metal stent in a stable position, a double pig-tail plastic stent $50 \mathrm{~mm} \times 7 \mathrm{Fr}$ (Advanix $^{\text {mi }}$ Biliary Stents, Boston Scientific, Marlborough, USA) was inserted along the conduit between the biliary and gastrointestinal tract [Video 1]. The patient had an uneventful recovery and the jaundice improved rapidly. He received chemotherapy for a high-grade B-cell lymphoma diagnosed on duodenal biopsies. A CT-scan performed one month later confirmed the correct position of both stents [Figure 2].

\section{DISCUSSION}

In patients with jaundice due to malignant obstruction, EUS-BD has been studied in recent years as an alternative to PTBD after failed ERCP. In 2001, Giovannini et al. ${ }^{[3]}$ were the first to report the creation of a bilioduodenal anastomosis under ultrasonographic guidance in a patient with pancreatic head cancer. Since then, experience has expanded, and various EUS-guided procedures for biliary tract diseases have been reported, including EUS-guided rendezvous choledochoduodenostomy, hepaticogastrostomy, and antegrade stent insertion ${ }^{[5-10]}$. Nowadays, ERCP and EUS-BD have similar success and complication rates in experienced hands, with a lower post-procedural pancreatitis rate after EUS-BD. Furthermore, recent studies have shown that EUS-BD is associated with better clinical success rates, lower adverse events rates, and fewer reinterventions than PTBD ${ }^{[11]}$. A study by Dhir et al. ${ }^{[7]}$ showed an average incidence of bile leaks of $3.9 \%$ in 432 patients; where most of the leaks were mild. Serious complications, such as stent migrations in the peritoneal cavity, sepsis, and perforations have rarely been described. Data on long-term stent patency are scant, but do not seem to differ significantly to that of ERCP stenting ${ }^{[7]}$.

With regards to the access route, transgastric and transduodenal endoscopic approaches have similar success rates and complications, of more than $90 \%$ and around $20 \%$ respectively $^{[12-16]}$. As a matter of fact, the access route is often determined more by the endoscopist's expertise or preference than by evidence-based indications. The transhepatic route through the stomach offers the advantage of a reduced bile leakage risk although the scope position is less stable, whereas the transduodenal route appears easier to manage because of direct access to the main biliary duct. In 2016, Tyberg et al. ${ }^{[17]}$ proposed an interesting approach to biliary drainage based on the anatomical condition of the patient as defined on cross-sectional 

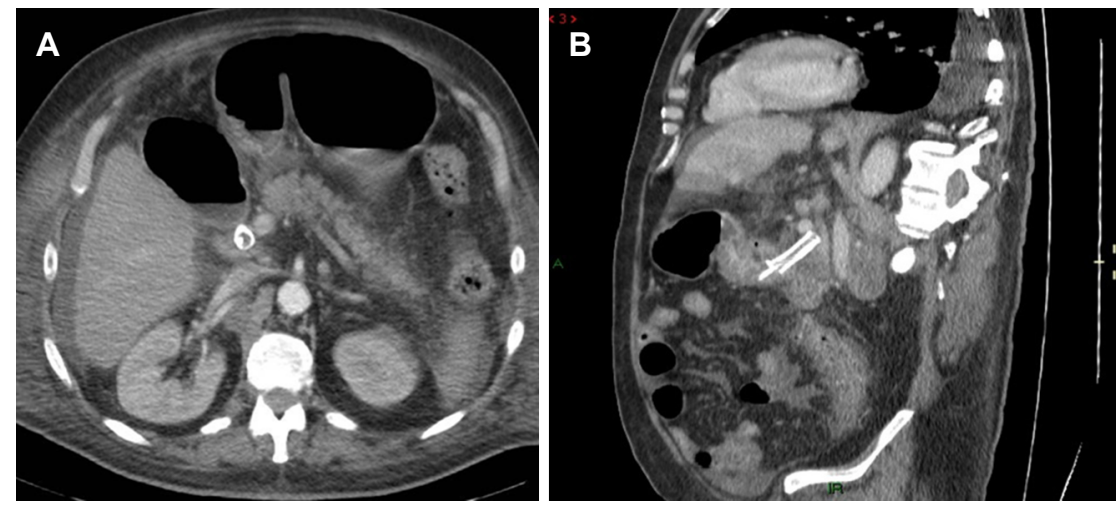

Figure 2. Control CT-scan on (A) axial plane and (B) sagittal reconstruction showing both plastic and metal stents in place

imaging. The authors defined an algorithm based on anatomy more than on the endoscopist's preference, so it required good technical experience with respect to different drainage procedures, which could also be applied in a sequential manner. Notably, they reported a high technical success rate (96\%) with a low rate of adverse events (10\%). In accordance with Tyberg's alghorithm, the first element to be evaluated is intrahepatic bile ducts dilation. If dilation is noted, anterograde stenting or hepatico-gastric drainage are suggested. If intrahpeatic ducts are not dilated, a rendezvous-based technique (from the intrahepatic or extrahepatic tract) is suggested. If this fails, transenteric stenting is still feasible. This interesting algorithm standardizes the EUS-BD approach for patients with biliary obstruction.

EUS-BD offers some clear advantages over ERCP. First, it does not require papillary cannulation, which carries out a risk of post-ERCP pancreatitis. Second, it allows creation of an anastomosis at a distance from the tumor, thus avoiding the risk of ingrowth or overgrowth with consequent stent dysfunction. Furthermore, EUS-BD can target different sites of the biliary tree, thus allowing drainage also in unfavorable situations both for ERCP, such as gastric outlet obstruction or post-surgical anatomy, and for PTBD such as ascites or liver lesions ${ }^{[18]}$. In comparison with PTBD, EUS-BD appears to be faster and more costsaving, since the procedure can be performed immediately after ERCP, thus avoiding repeated procedures and prolonged hospital stays ${ }^{[19-21]}$. On the other hand, performing this type of biliary recanalization may hamper endobiliary ablation, a technique used to control endobiliary tumor growth, and this may be a disadvantage of the EUS-BD technique. However, trans-luminal EUS-guided radiofrequency ablation by specifically designed active needles (such as EUSRA ${ }^{\mathrm{m}}$ RF Electrode-VIVA RF Generator, STARmed, Seoul, Korea or Habib ${ }^{m}$ EUS-RFA catheter, Emcision Ltd., London, UK) is feasible and probably facilitated by the absence of a standard biliary stent in the tract involved by a pancreatic tumor ${ }^{[22,23]}$.

In conclusion, even though we are still far from routine use of EUS-BD in common practice, it has been shown as a feasible and promising alternative to PTBD after failed ERCP. More emphasis on routine use of these procedures will come from recent development of dedicated accessories in addition to diffusion among endoscopists of the knowledge and practice of advanced ultrasonographic procedures.

\section{DECLARATIONS}

\section{Author's contributions}

Performed the procedure: Armellini E, Ballarè M

Drafted the paper: Armellini E

Edited the movie clip: Mazza F, Donato G

Revised the manuscript for relevant intellectual content: Orsello M, Occhipinti P 


\section{Availability of data and materials}

Not applicable.

\section{Financial support and sponsorship}

None.

\section{Conflicts of interest}

The author declares that there are no conflicts of interest.

\section{Ethical approval and consent to participate}

Ethical Board approval was not required.

\section{Consent for publication}

Not applicable.

\section{Copyright}

(c) The Author(s) 2018.

\section{REFERENCES}

1. Van Delden OM, Laméris JS. Percutaneous drainage and stenting for palliation of malignant bile duct obstruction. Eur Radiol 2008;18:448-56.

2. Wiersema M, Sandusky D, Carr R. Endosonography-guided cholangiopancreatography. Gastrointest Endosc 1996;43:102-6.

3. Giovannini M, Moutardier V, Pesenti C,Bories E, Lelong B, Delpero JR. Endoscopic ultrasound-guided bilioduodenalanastomosis: a new technique for biliary drainage. Endoscopy 2001;33:898-900.

4. Kunda R, Pérez-Miranda M, Will U, Ullrich S, Brenke D, Dollhopf M, Meier M, Larghi A. EUS-guided choledochoduodenostomy for malignant distal biliary obstruction using a lumen-apposing fully covered metal stent after failed ERCP. Surg Endosc 2016;30:5002-8.

5. Mallery S, Matlock J, Freeman ML. EUS-guided rendezvous drainage of obstructed biliary and pancreatic ducts: report of 6 cases. Gastrointest Endosc 2004;59:100-7.

6. Artifon EL, Marson FP, Gaidhane M, Kahaleh M, Otoch JP. Hepaticogastrostomy or choledochoduodenostomy for distal malignant biliary obstruction after failed ERCP: is there any difference? Gastrointest Endosc 2015;81:950-9.

7. Dhir V,Isayama H, Itoi T, Almadi M, Siripun A, Teoh AYB, Ho KY. Endoscopic ultrasonography-guided biliary and pancreatic duct interventions. Dig Endosc 2017;29:472-85.

8. Park do H, Koo JE, Oh J, Lee YH, Moon SH, Lee SS, Seo DW, Lee SK, Kim MH. EUS-guided biliary drainage with one-step placement of a fully covered metal stent for malignant biliary obstruction: a prospective feasibility study. Am J Gastroenterol 2009;104:216874.

9. Wang K, Zhu J, Xing L, Wang Y, Jin Z, Li Z. Assessment of efficacy and safety of EUS-guided biliary drainage: a systematic review. Gastrointest Endosc 2016;83:1218-27.

10. Khashab MA, Valeshabad AK, Afghani E, Singh VK, Kumbhari V, Messallam A, Saxena P, El Zein M, Lennon AM, Canto MI, Kalloo AN. A comparative evaluation of EUS-guided biliary drainage and percutaneous drainage in patients with distal malignant biliary obstruction and failed ERCP. Dig Dis Sci 2015;60:557-65.

11. Sharaiha RZ, Khan MA, Kamal F, Tyberg A, Tombazzi CR, Ali B, Tombazzi C, Kahaleh M. Efficacy and safety of EUS-guided biliary drainage in comparison with percutaneous biliary drainage when ERCP fails: a systematic review and meta-analysis. Gastrointest Endosc 2017;85:904-14

12. Artifon EL, Aparicio D, Paione JB, Lo SK, Bordini A, Rabello C, Otoch JP, Gupta K. Biliary drainage in patients with unresectable, malignant obstruction where ERCP fails: endoscopic ultrasonography-guided choledochoduodenostomy versus percutaneous drainage. J Clin Gastroenterol 2012;46:768-74.

13. Dhir V, Bhandari S, Bapat M, Joshi N, Vivekanandarajah S, Maydeo A. Comparison of transhepatic and extrahepatic routes for EUSguided rendezvous procedure for distal CBD obstruction. United Eur Gastroenterol J 2013;1:103-8.

14. Gupta K, Perez-Miranda M, Kahaleh M, Artifon EL, Itoi T, Freeman ML, de-Serna C, Sauer B, Giovannini M; InEBD STUDY GROUP. Endoscopic ultrasoundassisted bile duct access and drainage: multicenter, long-term analysis of approach, outcomes, and complications of a technique in evolution. J Clin Gastroenterol 2014;48:80-7.

15. Artifon EL, Marson FP, Gaidhane M, Kahaleh M, Otoch JP. Hepaticogastrostomy or choledochoduodenostomy for distal malignant biliary obstruction after failed ERCP: is there any difference? Gastrointest Endosc 2015; 81:950-9.

16. Dhir V, Artifon EL, Gupta K, Vila JJ, Maselli R, Frazao M, Maydeo A. Multicenter study on endoscopic ultrasound-guided expandable biliary metal stent placement: choice of access route, direction of stent insertion, and drainage route. Dig Endosc 2014;26:430-5.

17. Tyberg A, Desai AP, Kumta NA, Brown E, Gaidhane M, Sharaiha RZ, Kahaleh M. EUS-guided biliary drainage after failed ERCP: a novel algorithm individualized based on patient anatomy. Gastrointest Endosc 2016;84:941-6.

18. Khashab MA, Van der Merwe S, Kunda R, El Zein MH, Teoh AY, Marson FP, Fabbri C, Tarantino I, Varadarajulu S, Modayil RJ, Stav- 
ropoulos SN, Peñas I, Ngamruengphong S, Kumbhari V, Romagnuolo J, Shah R, Kalloo AN, Perez-Miranda M, Artifon EL. Prospective international multicenter study on endoscopic ultrasound-guided biliary drainage for patients with malignant distal biliary obstruction after failed endoscopic retrograde cholangiopancreatography. Endosc Int Open 2016;4:E487-96.

19. Artifon EL, Aparicio D, Paione JB, Lo SK, Bordini A, Rabello C, Otoch JP, Gupta K. Biliary drainage in patients with unresectable, malignant obstruction where ERCP fails: endoscopic ultrasonography-guided choledochoduodenostomy versus percutaneous drainage. J Clin Gastroenterol 2012;46:768-74.

20. Lee TH, Choi JH, Park do H, Song TJ, Kim DU, Paik WH, Hwangbo Y, Lee SS, Seo DW, Lee SK, Kim MH. Similar efficacies of endoscopic ultrasound-guided transmural and percutaneous drainage for malignant distal biliary obstruction. Clin Gastroenterol Hepatol 2016;14:1011-9.

21. Kawakubo K, Kawakami H, Kuwatani M, Kubota Y, Kawahata S, Kubo K, Sakamoto N. Endoscopic ultrasound-guided choledochoduodenostomy vs. transpapillary stenting for distalbiliary obstruction. Endoscopy 2016;48:164-9.

22. Song TJ, Seo DW, Lakhtakia S, Reddy N, Oh DW, Park DH, Lee SS, Lee SK, Kim MH. Initial experience of EUS-guided radiofrequency ablation of unresectable pancreatic cancer. Gastrointest Endosc 2016;83:440-3.

23. Pai M, Habib N, Senturk H, Lakhtakia S, Reddy N, Cicinnati VR, Kaba I, Beckebaum S, Drymousis P, Kahaleh M, Brugge W. Endoscopic ultrasound guided radiofrequency ablation, for pancreatic cystic neoplasms and neuroendocrine tumors. World J Gastrointest Surg 2015;7:52-9. 